\title{
Stable and Impact Analysis on Coal Production System Based on Impulse Process Theory
}

\author{
Wentao Liao ${ }^{1}$ and Xiaoyu Deng ${ }^{2, *}$ \\ ${ }^{1}$ Faculty of Resource and Safety Engineering, China University of Mining and Technology, Beijing 100083, China \\ ${ }^{2}$ Guizhou University of finance and economics, Guizhou 550001, China \\ ${ }^{*}$ Corresponding author
}

\begin{abstract}
At present, the coal industry through the energy structure adjustment and the impact of coal imports, as well as coal prices are low in China. With the change of coal production capacity, various influence factors of coal production system changes. This paper simplifies the various influence factors of coal production, building coal production system impulse process model, analysis the stability of the model base on impulse process theory; when some factors of the model are changed, the impact on the rest of the elements of change law were analyzed.
\end{abstract}

Keywords-coal production system; impulse process theory; stability; the impact analysis

\section{INTRODUCTION}

The rapid growth of China's economy triggered a series of such as ecological destruction, safety production and other economic and social problems ${ }^{[1]}$. In recent years, the rapid growth of China's economy slowing, lead to overcapacity of coal, coal enterprise profit fell sharply, and the prominent environmental problem. There is high speed development of economic and the sustainable development of balance and contradictions increasingly prominent. Blind to expand production on demand period, coal enterprises struggle when the economic downturn. As a result, government clearly put forward such as "green development, promote energy production and utilization way change" and "reasonable control of the total energy consumption" and so on new development concept officially listed in the state plan.

Coal production system mainly though to control macro economic, scientific management, this system overall efficiency control to achieve ${ }^{[2,3]}$. This paper probes into the above three aspects to simplify the control factors and expect reasonable explanation of the relevant factors in the process of coal production system, to build coal production system model base on impulse process theory. Then analysis of the stability of this model, and when some factors or some elements change in the model, its trend and change laws of the other elements were studied.

\section{ESTABLISHMENT OF AND STABILITY ANALYSIS OF THE} MODEL

\section{A. Establishment of Impulse Process Model}

Impulse process theory model to solve the question is: when one factors in the system change, prediction system evolution and trend of the various factors ${ }^{[4]}$.
It is vital to accurately and reasonably determine the research object and the relationship between various influencing factors in the modeling, and the reasonable simplification is indispensable. The relationship between factors is mainly according to the objective laws, government agencies guidelines and policies at the same time also is the basis. Coal production system adjustment base on impulse process model is composed of eight factors in this paper: coal production, coal prices, coal market demand, the capital sunk in coal, coal transport capacity, safety equipment and personnel quality , mining geological conditions ${ }^{[5]}$, social and environmental problems (see figure 1). Among them: $v_{8}$ are economic factors, $v_{4} v_{5} v_{6} v_{7} v_{8}$ are technological innovation, scientific management factors.

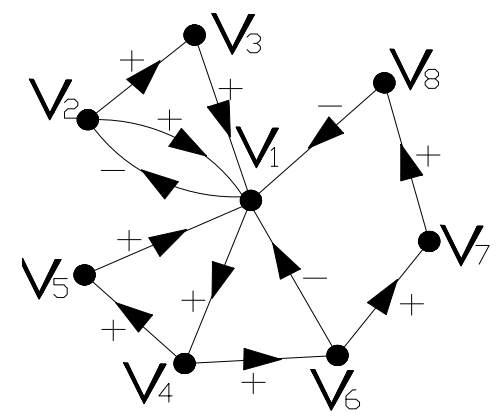

FIGURE 1 COAL PRODUCTION SYSTEM BASED ON IMPULSE PROCESS MODEL SIGNED DIRECTED GRAPH

$V_{1}{ }^{--}$coal production, $V_{2}^{--}$coal prices, $V_{3}^{--}$coal market demand, $V_{4}$-- the capital sunk in coal, $V_{5}$-- coal transport capacity, $V_{6}{ }^{--}$safety equipment and personnel quality , $V_{7}-$ mining geological conditions, $V_{8}$-- social and environmental problems

In figure 1, the relationship between matrix $\mathrm{A}$ is: 


$$
A=\left(a_{i j}\right)_{8 \times 8}=\left[\begin{array}{cccccccc}
0 & -1 & 0 & 1 & 0 & 0 & 0 & 0 \\
1 & 0 & 1 & 0 & 0 & 0 & 0 & 0 \\
1 & 0 & 0 & 0 & 0 & 0 & 0 & 0 \\
0 & 0 & 0 & 0 & 1 & 1 & 0 & 0 \\
1 & 0 & 0 & 0 & 0 & 0 & 0 & 0 \\
-1 & 0 & 0 & 0 & 0 & 0 & 1 & 0 \\
0 & 0 & 0 & 0 & 0 & 0 & 0 & 1 \\
-1 & 0 & 0 & 0 & 0 & 0 & 0 & 0
\end{array}\right]
$$

\section{B. The Stability Analysis of Impulse Process Model}

Obviously, figure 1 is a two-way communicating of rose charts for improvement. And $a_{k}$ denote a record length $k$ for closed-circuit Symbolic sum (when there is no length for closed-circuit, make $a_{k}=0$ ), set $r$ is the largest integer to $a_{r} \neq 0$, when $r>0$, stability condition of the system model base on impulse process is:

Theorem 1: The necessary conditions for the stability in system impulse process is

$$
\begin{gathered}
a_{r}= \pm 1 \\
a_{k}=-a_{r} a_{r-k}, k=1,2, \cdots, r-1
\end{gathered}
$$

Theorem 2: if the impulse process of the system is stability, then the sufficient and necessary conditions for the stable value is ${ }^{[3]}$

$$
\sum_{k=1}^{r} a_{k} \neq 1
$$

Therefore, by figure 1 and theorem 1 and 2, it can be calculated as shown below $\quad a_{1}=0 \quad, \quad a_{2}=(-1) v_{1} v_{2} \times(+1) v_{2} v_{1}=-1$, $a_{3}=(-1) v_{1231}+(+1) v_{1451}+(-1) v_{1461}=-1 \quad, \quad a_{4}=0$, $a_{5}=(+1) v_{14678}=-1 \quad$, meet formula $a_{2}=-a_{5} a_{3}=-1, a_{3}=-a_{5} a_{2}=-1$, come into existence, meet formula(2).

Moreover,

$\sum_{k=1}^{r} a_{k}=a_{2}+a_{3}+a_{5}=(-1)+(-1)+(-1)=-3 \neq 1$, meet the formula (3). Therefore, the calculation results of impulse model meet the necessary and sufficient conditions for the stability of the impulse process, system is stable, and the model is reasonable. It should be pointed out that, when the impulse process model does not meet the above formula (1) or (2) or (3), it must be adjust impulse process model parameter, make it at the same time in accordance with formula (1), (2) and (3).
Adjust the impulse model related to the "+" and "-" make the model stability, the reason can be directly in the corresponding relationship model for explanation.

\section{IMPUlSE PROCESS MOdEL INFLUENCE TREND PREDICTION}

\section{A. Relationship of Factor in the Model}

In the brief analysis of the model, for example: the model of, economic theory can well explain the relationship between the coal production, coal price and coal market .Coal production increase leads to the price of coal is lower, the increase of coal demand will inevitably require larger coal production capacity . But coal macro economic changes is extremely complex, in a certain period of time, the relationship is not a constant. Therefore, the model is a kind of research hypothesis ${ }^{[6]}$. In model "+" or "-" is a factor for positive to the next element, or promote the refund.

\section{B. Prediction and Analysis of Impulse Process Model}

The directed graph adjacency matrix A is write in figure 1, according to hypothesis of the impulse process, expressed as $v_{i}(t)$ factor $v_{i}$ value in session $t, p_{i}(t)$ said amount of impulse change of factor $v_{i}(t)$ in session $t$, and according to the meaning of the adjacency matrix $W$ can described as follow:

$$
\begin{gathered}
v_{i}(t+1)=v_{i}(t)+p_{i}(t+1), i=1,2, \ldots, 8, t=0,1,2, \ldots \\
p_{j}(t+1)=\sum_{i=1}^{n} w_{i j} p_{i}(t), j=1,2, \ldots, 8, t=0,1,2, \ldots
\end{gathered}
$$

Row

$$
\begin{aligned}
& v(t)=\left(v_{1}(t), v_{2}(t), v_{3}(t), v_{4}(t), v_{5}(t), v_{6}(t), v_{7}(t), v_{8}(t),\right), \\
& p(t)=\left(p_{1}(t), p_{2}(t), p_{3}(t), p_{4}(t), p_{5}(t), p_{6}(t), p_{7}(t), p_{8}(t),\right) .
\end{aligned}
$$

The formula (4), (5) can be represented as:

$$
\begin{gathered}
v(t+1)=v(t)+p(t+1), t=0,1,2, \ldots \\
p(t+1)=p(t) W, t=0,1,2, \ldots
\end{gathered}
$$

The average $\bar{v}(t)=\frac{1}{7} \sum_{i=1}^{7} v_{i}(t)$ value of various factors at different moment reflect the change of coal production to the influence degree of various factors, a plus sign is expressed as positive, a minus sign is expressed as the refund. The average momentum $\delta^{2}(t)=\frac{1}{7} \sum_{i=1}^{7}\left(v_{i}(t)-\bar{v}(t)\right)^{2}$ value which different factors affecting the coal production system in session $t$, reflect coal production change affect the coordination of other factors on model, $\delta^{2}(t)$ is the smaller ,the better. 
So, set $v(0)=p(0)$, and here is a sudden increase in the initial session of coal production $v_{1}$, namely $p(1.0,0,0,0,0,0,0)$, using the formula (6) and (7) will be able to predict the change trend of other factors.

TABLE I. THE INFLUENCE OF OTHER FACTORS IN THE SYSTEM

\begin{tabular}{|c|c|c|c|c|c|c|c|c|}
\hline \multicolumn{7}{|c|}{$p(t)$} \\
\hline & $p_{1}(t)$ & $p_{2}(t)$ & $p_{3}(t)$ & $p_{4}(t)$ & $p_{5}(t)$ & $p_{6}(t)$ & $p_{7}(t)$ & $p_{8}(t)$ \\
\hline 0 & 0.14 & 0.14 & 0.14 & 0.14 & 0.14 & 0.14 & 0.14 & 0.14 \\
\hline 1 & 0.43 & 0.43 & 0.29 & 1.29 & 0.14 & 1.00 & 0.14 & 1.00 \\
\hline 2 & 0.71 & 1.43 & 0.29 & 3.86 & 0.43 & 1.29 & 0.14 & 1.43 \\
\hline 3 & 1.00 & 3.57 & 0.29 & 18.7 & 0.43 & 4.71 & 0.43 & 3.57 \\
\hline 4 & 1.00 & 5.57 & 0.86 & 79.3 & 0.71 & 14.4 & 0.43 & 14.1 \\
\hline 5 & 0.71 & 8.29 & 1.43 & 324 & 1.29 & 28.7 & 0.14 & 26.6 \\
\hline
\end{tabular}

\begin{tabular}{|c|c|c|c|c|c|c|c|c|}
\hline \multicolumn{10}{|c|}{$v(t)$} \\
\hline$t$ & $v_{1}(t)$ & $v_{2}(t)$ & $v_{3}(t)$ & $v_{4}(t)$ & $v_{5}(t)$ & $v_{6}(t)$ & $v_{7}(t)$ & $v_{8}(t)$ \\
\hline 0 & 0 & 0 & 0 & 0 & 0 & 0 & 0 & 1 \\
\hline 1 & 1 & -1 & 0 & 1 & 0 & 0 & 0 & 1 \\
\hline 2 & 1 & -2 & 1 & 2 & 1 & -1 & 0 & 1 \\
\hline 3 & 3 & -2 & 2 & 2 & 2 & -6 & 0 & 1 \\
\hline 4 & 12 & -4 & 2 & 4 & 2 & -17 & 0 & 1 \\
\hline 5 & 30 & -13 & 4 & 13 & 4 & -36 & 0 & 1 \\
\hline
\end{tabular}

It can be seen from table I, when coal production suddenly increase, as time goes on, $p_{2}(t)$ which is the price of coal, and $p_{6}(t)$ which is the safety facilities and personnel quality have a negative impact. Coal production increase will inevitably affect the price of coal, which conform to the principles of economics; and when coal output increase, overall production safety accident will increase. Safety facilities and personnel quality are important factors of affect the safety in production accident. In pursuit of yield, such as illegal operation and paralysis unsafe acts will be increased, production safety accidents increase.

It is shown from $\bar{v}(t)$, overall the coal production system is positive. Coal prices have fallen, safety accident may increase, but with the increase of coal enterprises safety investment, the progress of science and technology, to improve the poor geological conditions, coal enterprises safety equipment constantly updated, and gradually solve the problems of society and the environment. It is shown from $\delta^{2}(t)$, if coal production single increase in the system , $\delta^{2}(t)$ value growth speed, collaborative coal production system is low.

Likewise, the production practice control of single factor listed its impulse process: when $\mathrm{a}_{12}=1$, namely control the price of coal; when $\mathrm{a}_{13}=1$, the control of coal market demand; when $\mathrm{a}_{41}=1$, when the coal capital investment; when $\mathrm{a}_{81}=1$, the social and environmental. Respectively into the formula (6) and (7).The calculation results are shown in table II as follows:
TABLE II. THE INFLUENCE OF OTHER FACTORS IN THE SYSTEM

\begin{tabular}{|c|c|c|c|c|c|c|c|}
\hline $\bar{v}(t)$ & $\delta^{2}(t)$ & $\bar{v}(t)$ & $\delta^{2}(t)$ & $\bar{v}(t)$ & $\delta^{2}(t)$ & $\bar{v}(t)$ & $\delta^{2}(t)$ \\
\hline 0.14 & 0.14 & 0.14 & 0.14 & 0.14 & 0.14 & 0.14 & 0.14 \\
\hline 0.43 & 0.43 & 0.29 & 1.29 & 0.14 & 1.00 & 0.14 & 1.00 \\
\hline 0.71 & 1.43 & 0.29 & 3.86 & 0.43 & 1.29 & 0.14 & 1.43 \\
\hline 1.00 & 3.57 & 0.29 & 18.71 & 0.43 & 4.71 & 0.43 & 3.57 \\
\hline 1.00 & 5.57 & 0.86 & 79.29 & 0.71 & 14.43 & 0.43 & 14.14 \\
\hline 0.71 & 8.29 & 1.43 & 323.86 & 1.29 & 28.71 & 0.14 & 26.57 \\
\hline \multicolumn{2}{|c|}{$\mathrm{a}_{12}=1$} & \multicolumn{2}{|c|}{$\mathrm{a}_{13}=1$} & \multicolumn{2}{|c|}{$\mathrm{a}_{41}=1$} & $\mathrm{a}_{81}=1$ \\
\hline
\end{tabular}

According to the data in the table II, the above control measures have a certain advantage. For $\bar{v}(t)$, arrived at some point has certain decline, which does not work once and for all. In a certain moment should adjust relevant control measures. For $\delta^{2}(t)$, Compared with the results by above control measures, it can be shown that coal production system coordination degree is higher when control the price of coal.

When we consider more factors control, that is, at the same time two factors control are that when $\mathrm{a}_{41}=1, \mathrm{a}_{81}=1$; Three factors control are that when $\mathrm{a}_{41}=1, \mathrm{a}_{81}=1, \mathrm{a}_{13}=1$; The above four factors are controlled at the same time, Respectively into the formula (6), (7). The calculation results are shown in table III as follows:

TABLE III. THE INFLUENCE OF MULTIPLE FACTORS CHANGE

\begin{tabular}{|c|c|c|c|c|c|}
\hline $\bar{v}(t)$ & $\delta^{2}(t)$ & $\bar{v}(t)$ & $\delta^{2}(t)$ & $\bar{v}(t)$ & $\delta^{2}(t)$ \\
\hline 0.14 & 0.14 & 0.14 & 0.14 & 0.14 & 0.14 \\
\hline 0.14 & 1.00 & 0.29 & 1.29 & 0.57 & 0.14 \\
\hline 0.43 & 1.29 & 0.57 & 3.43 & 1.14 & 1.71 \\
\hline 0.71 & 3.00 & 1.14 & 11.57 & 3.14 & 13.86 \\
\hline 1.00 & 9.29 & 2.14 & 40.29 & 3.86 & 35.71 \\
\hline 1.29 & 8.14 & 3.14 & 95.43 & 6.00 & 185.14 \\
\hline & & \multicolumn{2}{|c|}{$\mathrm{a}_{41}=1, \mathrm{a}_{81}=1}$, & $\begin{array}{c}\mathrm{a}_{12}=1, \\
\mathrm{a}_{81}=1,\end{array} \mathrm{a}_{41}=1$, \\
\hline
\end{tabular}

After taking multiple factors control from table III shows that the control effect of multiple factors is better than single factor control from the point of $\bar{v}(t)$ values, promoting effect is obvious; From $\delta^{2}(t)$, when $\mathrm{a}_{41}=1$, $\mathrm{a}_{81}=1$, the system is the best coordination.

\section{CONCLUSION}

(1)Impulse process model established by this paper is a roses charts for two-way communicating, using impulse process stability analysis theorem 1,2 , shows that model meet the necessary and sufficient conditions for the stability of the impulse process, the impulse process model is reasonable. 
(2)Impulse process model established by this paper has carried on the forecast and impulse process analysis, the prediction results and the measures taken in the production practice effect was consistent, model prediction and the results of the analysis in the impulse process model is credible. Therefore, this model can be used as such a research method of the problem.

(3)Through analysis of impulse process model, further explained the growth of coal production, control of coal mine safety accidents related regulation and control of the government are inseparable. Coal mine related functions of the government management should be based on different period of coal prices, market, coal production, and coal mine related social and environmental problems, formulate corresponding policies and measures simultaneously, in strict accordance with the relevant laws and regulations to monitor coal mine.

\section{REFERENCES}

[1] Li.H.M,and Fu.K, "Some major technical problems and countermeasures for deep mining," Journal of Mining and Safety Engineering. vol.04, pp.468-471, 2006.

[2] Liu.H.B,Cong.W, and Li.X,"The building of indicators system for regulation policies of coal production capacity,” China Mining Magazine.vol.22(8),pp.18-23,2013.

[3] Liu.H.B,and Wu B.S, "Coal production capacity controls based on GDP,” Resources and Industries.vol.3(16),pp.44-50,2014.

[4] Jiang.Q.Y,and Xie.J.X. Mathematical Model [M]. pp.248-253,2006.(In Chinese)

[5] Guo.F,and .Y.L,“Mine geology on the quality of the raw coal,”Coal Technology.vol.12(21),pp.214-216,2002.

[6] Liu.X“Stable analysis on supply chain system based on pulse process theory,”International Symposium on Intelligent Information Technology Application Workshops,pp.894-897,2008. 